\title{
Rabies Virus Infection of Cultured Adult Mouse Dorsal Root Ganglion Neurons
}

\author{
Jaime Castellanos, Hernán Hurtado* ${ }^{+}$, Janeth Arias, Alvaro Velandia
}

Subdirección Industrial * Laboratorio de Neurobiología, Instituto Nacional de Salud, Av. El Dorado Carrera 50,
Bogotá, Colombia

An in vitro model of adult dorsal root ganglion neurons infection by rabies virus is described. Viral marked neurotropism is observed, and the percentage and the degree of infection of the neurons is higher than in non neuronal cells, even if neurons are the minority of the cells in the culture. The neuritic tree is also heavily infected by the virus.

Key words: adult mouse - cell culture - dorsal root ganglion - infection - neuron - neurotropism - rabies

Rabies virus targets are mainly located in the central nervous system (CNS). Most pathological effects of this viral infection take place there (Jackson \& Reimer 1989, King \& Turner 1993, Mrak \& Young 1994). However, it is known that rabies virus use the retrograde axoplasmic transport in order to arrive to the CNS where it expresses its pathogenic role, and gives rise to a fatal encephalopathy. In vivo evidences, show that uptake and transmission of the virus by the peripheral nervous system are fundamental steps in the infection. Interruption of retrograde axoplasmic transport by ligation, sectioning or local aplication of some drugs (capable of inhibiting the assembly of microtubules) can prevent the in vivo infection (Baer et al. 1965, 1968, Tsiang 1993, King \& Turner 1993, Mrak \& Young 1994). Dorsal root ganglion (DRG) neurons are believed to be a crucial bridge allowing rabies virus to pass from periphery to CNS. In experimental animals, immunofluorescent virus particles have been observed in DRG neurons (Charlton \& Casey 1979). Intramuscular injections of virus suspensions results in an early arrival of the virus to sensory neurons (18$60 \mathrm{hr}$ postinfection) and the number of infected cells increase with time (Murphy et al. 1973, Coulon et al. 1989). In vitro experiments demonstrate that DRG neurons are capable to transport the virus in both, retrograde and anterograde directions (Tsiang et al. 1989). However, all reported in vitro experiments involving DRG neurons and rabies virus are made using embryonic tissues (Tsiang et al. 1983, Lycke \& Tsiang 1987, Mrak $\&$ Young 1994) which are different from the adult

\footnotetext{
${ }^{+}$Corresponding author. Fax: 905712223055

Received 27 January 1996

Accepted 23 May 1996
}

cells. For example, the growth factor dependence of DRG neurons changes with time as shown in in vitro (Buchman \& Davies 1993) and knockout experiments (Klein 1994). The majority of DRG neurons from adult animals survive in NGF-immunized animals, but embryonic DRG neurons do not (Rich et al. 1985). In addition, sciatic section in newborn animals results in a higher DRG neurons mortality than the same procedure in adult animals (Otto et al. 1987). Finally, adult isolated DRG neurons can be maintained in culture without the addition of growth factors. In contrast, embryonic DRG neurons, require NGF in order to survive (Eichler \& Rich 1989, Ruit et al. 1992).

In other models of viral infection, the degree of differentiation attained by the neurons determines some aspects of the infection. For example, HIV-1 gene expression and replication in neuronal and glial cell lines are augmented by the addition to the cell of nerve growth factor at concentrations which induces neuronal differentiation (Ensoli et al. 1994). In contrast, the infection of human SHSY5Y neuroblastoma cells by HIV-1 is inhibited by differentiating agents like retinoic acid or dibutyril cAMP (Vesanen et al. 1994). Human cytomegalovirus replication in HCN-1A cells (a neuronal cell line) largerly depends on differentiation. Release of infectious progeny from the differentiated cells is greater by 100 - to -1000 fold, and the cytopathic effect appeared earlier and is more pronounced in differentiated cells (Poland et al. 1994).

Considering that DRG neurons are an entry door to the CNS, that DRG neurons from adults are known to be different from the embryonic neurons, and that viral infection and replication varies depending on the differentiation degree of the neurons, we have decided to study the in vitro infection of adult neurons by rabies virus. Our results show a high degree of neurotropism of rabies virus toward adult mouse DRG neurons. This sys- 
tem may represent an usefull tool to understand important steps in rabies infection as binding and entry to the adult neurons, and viral replication and transport.

\section{MATERIALS AND METHODS}

Virus - The Challenge Virus Standard (CVS) strain of fixed rabies virus was used. Virus were obtained from supernatants of BHK-21 infected cells. Cell monolayers were cultured on $75 \mathrm{~cm}^{2}$ plastic flasks and infected at confluence with $2 \mathrm{ml}$ viral suspension $\left(10^{5,5} \mathrm{LD}_{50}\right)$. The cells were incubated for 4 days at $33^{\circ} \mathrm{C}$ in Minimun Essential Medium without fetal calf serum. The culture flasks were frozen and thawed twice to recover intracellular virus, the supernatants were centrifuged to remove cell debris, divided into aliquots and stored at $-70^{\circ} \mathrm{C}$ until use (Kaplan \& Koprowski 1973).

Titration of virus - In vivo, virus titers were obtained using intracerebral injection in young mice. Animals were observed daily, and deaths were recorded. In vitro, virus titers were obtained by counting the number of fluorescent foci in VERO infected cells (Kaplan \& Koprowski 1973).

Dorsal root ganglion cell cultures - Two 18$20 \mathrm{~g}$ ICR mice were used per culture. The animals were killed by cervical dislocation, followed by removal of the vertebral column under a laminar flow hood. Ganglia were collected with forceps in DMEM with antibiotics, and dissociated with collagenase ( $1 \mathrm{mg} / \mathrm{ml}$ prepared in DMEM) during 2 hr. Dissociation was completed by pipeting through a narrow mouth Pasteur pipete. The cell suspension was centrifuged $(200 \mathrm{x} \mathrm{g}, 10 \mathrm{~min})$, the supernatant was discarded and the pellet resuspended in $1 \mathrm{ml}$ of DMEM supplemented with $10 \%$ fetal calf serum (FCS). After counting in an hemocytometer, 1000 living (Trypan blue negative) neurons/well were seeded on 24 well dishes with round glass coverslips coated with poli-l-lisine $(10 \mu \mathrm{g} / \mathrm{ml})$. After $48 \mathrm{hr}$ in culture, the medium was changed and replaced by DMEM additioned with cytosine arabinoside $\left(10^{-5} \mathrm{M}\right)$ in order to reduce the proliferation of non neuronal cells. Three days after, the cultures were ready for infection (Matsumoto et al. 1974, Lycke \& Tsiang 1987).

Infection of DRG cell cultures - On fifth day, the medium were washed and the cultures were infected with $500 \mu \mathrm{l}$ of $10^{-1}$ or $10^{-2}$ dilution (in DMEM $+10 \%$ FCS) of the stock rabies virus suspension. After incubation $6 \mathrm{hr}$ at $37^{\circ} \mathrm{C}$, the inoculum was removed and replaced with fresh culture medium without cytosine arabinoside and incubated for $48 \mathrm{hr}$. To define if the infection detected needs live virus, some cells were infected with U.V. inactivated virus. In addition to define if detect- able binding of the virus occurs only to living cells, some paraformaldehyde fixed DRG cultures were infected.

Fluorescence - Controls and rabies virus infected cultures were processed with a hamster antirabies IgG conjugated with fluorescein isothiocyanate, diluted 1/30 in Evans blue. The fluorescent conjugate was prepared by Immunology and Virology Laboratories of the National Institute of Health from Colombia. The coverslips with the cultures were washed with phosphate buffered saline ( $\mathrm{pH}$ 7.0), fixed with paraformaldehyde $4 \%$ for $30 \mathrm{~min}$ at room temperature, washed, permeabilized with $0.1 \%$ Triton X-100 and incubated at $37^{\circ} \mathrm{C}$ with the conjugated antibody for 30 min. Incubation for $10 \mathrm{~min}$ at room temperature with bisbenzimide $(5 \mathrm{mg} / 100 \mathrm{ml})$ was followed by washing with distilled water, air drying and mounting with buffered glycerol, $\mathrm{pH}$ 9.0. Cultures were observed and photographed under fluorescence epiillumination. Control wells were processed in a similar fashion, but in the absence of rabies virus or in the absence of primary antibody. In order to control if the viral particles were located within the cells, some infected cells were treated for immunodetection, but without permeabilization.

Quantification - Counts were made on color photographic prints. Eigth random views of each coverslip were photographed twice (one with fluorescein and other with bisbenzimide filters). Total number of cells was determined by counting the number of nuclei (stained by bisbenzimide). The number of infected cells was determined by counting the number of fluorescein labeled cells. Neurons were identified by their large size and characteristic morphology in culture (round soma and well developed neuritic tree). Cell numbers were expressed as total number of cells (infected, uninfected, neurons, non neuronal cells). Data were obtained from eleven wells of $10^{-1}$ dilution and ten wells of $10^{-2}$ virus dilution.

Statistical analysis - Data reported here were obtained from three different cultures. In order to define if cultured adult DRG neurons were preferentially infected by rabies virus (neurotropism), Chi-square tests were used to compare (for each dilution of virus) the total number of infected versus uninfected neurons and non neuronal cells. We have also tested if the dilution $\left(10^{-1}\right.$ or $\left.10^{-2}\right)$ of the virus interferes with the total number of infected neuronal or non neuronal cells.

\section{RESULTS}

Morphology - Phase contrast - All cultures (infected and uninfected) presented large cells with highly refringent soma and well developed neuritic trees (Fig. 1). These morphological features 


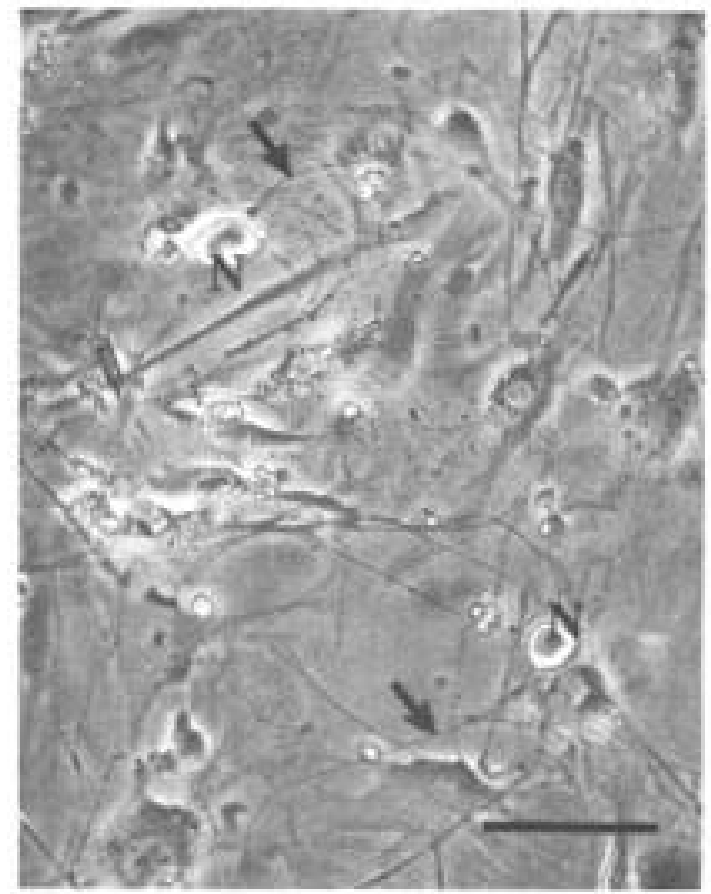

Fig. 1: phase contrast aspect of infected DRG cell cultures. Neurons $(\mathrm{N})$ with large, refringent round soma and well developed neuritic tree (arrows) are present. Many non neuronal are also observed. Bar $=100 \mu \mathrm{m}$.

were characteristic of healthy DRG neurons. A large number of nonneuronal cells were also present in the cultures. Immunofluorescence - DRG cells showed a variable degree of infection depending on cell type. Many neurons are infected and many of them heavily. The soma from infected neurons appeared as large immunofluorescent spheres with well labelled neuritic trees (Fig. 2a). Most non neuronal cells were also infected but not as heavily as neurons (Fig. 2b). Mock infected cultures were used as control and were devoided of detectable immunoreactivity (Fig. 2c). Non permeabilized cultures showed a faint labeling in a small number of cells (data not shown). Fixed cultures showed no immunoreactivity.

Quantification - No statistical differences were detected in the three cultures used in each dilution therefore we pool data from all of them. For dilution at $10^{-1}$, total cell counts showed that neurons were the minority of cells in the cultures (19.42\%). However, the immunofluoresce data indicated that $81.41 \%$ of the neurons and $25.81 \%$ of the non neuronal cells were infected by rabies virus and this difference was statistically significative $(\mathrm{p}<0.001)$. For dilution $10^{-2}$ the results are similar $(\mathrm{p}<0.001)$ (Table). The percentage of neurons was only $17.59 \%$, but $81.61 \%$ of them was infected. Non neuronal cells represented $82.41 \%$ of the total, but
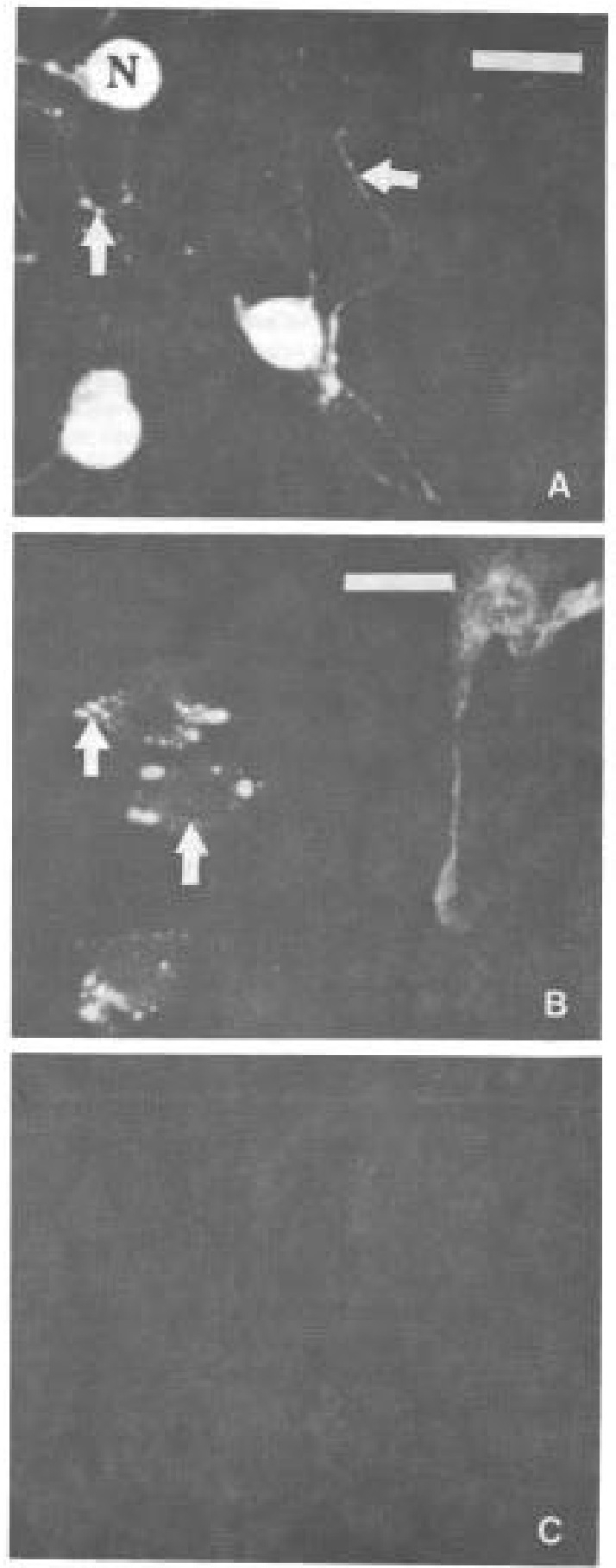

Fig 2: immunofluorescence detection of infected cells (exposure time of $60 \mathrm{sec}$ for all photographies). A: adult DRG cells heavily infected by rabies virus appear as large immunofluorescent spheres $(\mathrm{N})$. Neuritic trees are also infected (arrows). B: infected non neuronal cells are shown (arrows). They are not as heavily labeled as neurons. C: control uninfected DRG cell cultures. No virus was added and the culture was processed for immunohistochemistry. No immunoreactive cells are present. $\mathrm{Bar}=50 \mu \mathrm{m}$. 
TABLE

Comparison of neuronal vs non neuronal cells infected with two viral dilutions

\begin{tabular}{lccccc}
\hline & \multicolumn{2}{c}{ Dilution 1} & & \multicolumn{2}{c}{ Dilution 2 } \\
\cline { 2 - 3 } \cline { 6 - 7 } & Infected & Uninfected & & Infected & Uninfected \\
\hline Neurons & 609 & 139 & & 688 & 155 \\
Non neuronal cells & 801 & 2,302 & & 626 & 3,323 \\
\hline Total & 1,410 & 2,441 & & 1,314 & 3,478 \\
\hline
\end{tabular}

Neurons exhibit a high risk of infection. Relative risk $=3.15, \mathrm{p}<0.001$ (dilution 1). Relative risk $=5.15, \mathrm{p}<0.001$ (dilution 2). No differences in neuronal infection are observed between dilutions 1 and 2. p>0.05. Non neuronal cells infection is smaller in dilution 2 compared to dilution $1 . \mathrm{p}<0.001$.

only $15.85 \%$ of them were infected. This difference in degree of infection between neuronal and non neuronal cells was also highly significative $(\mathrm{p}<0.001)$.

For the two dilutions tested, there were no statistical differences in the number of infected and uninfected neurons $(p>0.05)$, but in dilution $2\left(10^{-2}\right)$ the number of non neuronal cells infected was smaller than in dilution $1\left(10^{-1}\right)(\mathrm{p}<0.001)$. In other words, non neuronal cells presented a higher risk of infection (relative risk 1.53) with dilution 1 than with dilution 2 .

\section{DISCUSSION}

The relative susceptibility of different cell types from DRG ganglia was explored in vitro, and assuming that all cells were in a real monolayer, they should be equally accessible to the virus. Even if neurons represent only a minority of the cells in our cultures (about one fifth), most of them were infected and the neuritic tree was conspicously invaded by rabies virus. This neurotropism is in good agreement with the experiments carried out using embryonic DRG cells: in 1983, Tsiang and coworker showed that embryonic (E15) mouse DRG cells were infected by rabies virus. Licke and Tsiang (1987), using E15-E17 wistar rats DRG cells established that rabies virus was taken by DRG neurons and retrogradely transported in vitro. In 1989 Tsiang and coworkers also demonstrate de existence of anterograde transport of rabies virus by embryonic DRG rat neurons. However, to the best of our knowledge, no published data exists on the in vitro infection of adult DRG neurons by rabies virus. It is well known that embryonic DRG neurons are different in many aspects from adult DRG neurons. Depending on the developmental stage, embryonic DRG neurons need NGF, BDNF or NT-3 for their survival (Eichler \& Rich 1989, Buchman \& Davies 1993). In contrast, the vast majority of adult rat DRG neurons survive in culture in the absence of NGF or other neurotrophic factors (Lindsay \& Harmar 1989). Besides, it has been demonstrated that the percentage of DRG neurons expressing mRNA from the nicotinic receptor $\alpha 3$ subunit varies with age, from a $14 \%$ at E8 to $22 \%$ at 1 month postnatal (Boyd et al. 1991). This observation is particularly important if nicotinic receptors participate on the initial steps of the infection. As already stated, viral infection and replication may also depend on the developmental age of the neurons (Ensoli et al. 1994, Polland et al. 1994, Vesanen et al. 1994).

The reason for the high susceptibility of neurons to be infected by rabies virus is still unknown. It is believed that the virus interact with membrane receptors before entering the cells. The exact nature of these receptors is under considerable controversy. Glycolipids and nicotinic acetylcholine receptors are the most accepted candidates (King $\&$ Turner 1993). Both type of molecules are expressed by DRG cells (Halvorsen \& Berg 1986) but the knowledge on nicotinic receptors on these cells is still fragmentary. An interesting finding was the observation that neurons are not susceptible to a "dilution effect" (at least in the range used). On the other hand, it appears that non neuronal cells are less affected when the viral suspension are diluted. This phenomenon stress the in vitro expression of rabies virus neurotropism. We have no explanation for this difference, but it would be tempting to especulate that at higher dilutions, it is possible to distinguish between some kind of "specific binding"(in neurons) from "unespecific binding" in non neuronal cells.

It is important to consider another important fact. In vitro, as well as in vivo, DRG neurons exhibit an important neuritic tree. An interesting posibility that may help to understand the high levels of infection of neurons is the fact that the neuritic tree represents a large amount of the membrane and cytoplasm of the DRG neurons. Indeed, in vitro, neurites are often heavily infected by rabies virus. This is in agreement with the capability 
of DRG cells to transport rabies virus in both directions (retrograde and anterograde). A possible scenario is that DRG neurons in vitro, increase their contact surface with the virus by means of their neuritic tree. If this increase is combined with the presence of "receptors" the high levels of infection supported by DRG neurons can be explained.

We can conclude that adult DRG cells can be infected in vitro by rabies virus. In addition the virus show a high tropism towards DRG neurons, even in conditions where much more non neuronal cells than neurons are present in the cultures.

\section{REFERENCES}

Baer GM, Shantha RT, Bourne GH 1968. The pathogenesis of street rabies virus in rats. Bull Wld Hlth Org 38: 119-25.

Baer GM, Shanthaveerappa TR, Bourne GH 1965. Studies on the pathogenesis of fixed rabies virus in rats. Bull Wld Hlth Org 33: 783-94.

Boyd RT, Jacob MH, McEachern AE, Caron S, Berg DK 1991. Nicotinic acetylcholine receptor mRNA in dorsal root ganglion neurons. J Neurobiol 22: 114.

Buchman V, Davies A 1993. Different neurotrophins are expressed and act in a developmental sequence to promote the survival of embryonic sensory neurons. Development 118: 989-1001.

Charlton KM, Casey GA 1979. Experimental rabies in skunks. Immunofluorescence light and electron microscopic studies. Lab Invest 41: 36-44.

Coulon P, Derbin C, Kucera P, LaFay F, Prehaud C, Flamand A 1989. Invasion of the peripheral nervous system of adult mice by the CVS strain of rabies virus and its avirulent derivative $\mathrm{AvO1} . J$ Virol 63: 3550-54.

Eichler ME, Rich K 1989. Death of sensory ganglion neurons after acute withdrawal of nerve growth factor in dissociated cell cultures. Brain Res 482: 340346.

Ensoli F, Ensoli B, Thiele CJ 1994. HIV-1 gene expresion and replication in neuronal and glial cell lines with immature phenotype: effects of nerve growth factor. Virol 200: 668-676.

Halvorsen SW, Berg DK 1986. Identification of a nicotinic acetylcholine receptor on neurons using and aneurotoxin that blocks receptor function. $J$ Neurosci 6: 3405-12.

Jackson AC, Reimer DL 1989. Pathogenesis of experimental rabies in mice: an immunohistochemical study. Acta Neuropathol 78: 159-65.

Kaplan MM, Koprowski H 1973. Laboratory techniques in rabies. Monograph Series 23, 3rd ed. Geneve, WHO.

King AA, Turner GS 1993. Rabies: a review. J Comp Pathol 108: 1-39.

Klein R 1994. Role of neurotrophins in mouse neuronal development. FASEB $J$ 8: 738-44.

Lindsay RM, Harmar AJ1989. Nerve growth factor regulates the expression of neuropeptide genes in adult sensory neurons. Nature 337: 362-364.

Lycke E, Tsiang H 1987. Rabies virus infection of cultured rat sensory neurons. J Virol 61: 2733-41.

Matsumoto S, Schneider LG, Kawal A, Yonezawa T 1974. Further studies on the replication of rabies and rabies-like viruses in organized cultures of mammalian neural cells. $J$ Virol 14: 981-996.

Mrak RE, Young L 1994. Rabies encephalitis in humans: pathology, pathogenesis and pathophysiology. $J$ Neuropathol Exp Neurol 53: 1-10.

Murphy FA, Bauer SP, Harrison AK, Winn WC 1973. Comparative pathogenesis of rabies and rabies-like viruses. Viral infection and transit from inoculation site to the central nervous system. Lab Invest 28: $361-76$

Otto D, Unsicker K, Grothe C 1987. Pharmacological effects of nerve growth factor and fibroblast growth factor applied to the transectioned sciatic nerve on neuron death in adult rat dorsal root ganglia. Neurosci Lett 83: 156-60.

Poland SD, Bambrick LL, Dekaban GA, Rice GP 1994. The extent of human cytomegalovirus replication in primary neurons in dependent on host cell differentiation. J Infect Dis 170: 1267-1271.

Rich KM, Yip HK, Osborne PA, Schmidt RE, Johnson EM 1985. Role of Nerve Growth Factor in the adult dorsal root ganglia neuron and its response to injury. J Comp Neurol 230: 110-18.

Ruit KG, Elliott JL, Osborne PA, Yan Q, Snider WD 1992. Selective dependence of mammalian dorsal root ganglion neurons on nerve growth factor during embryonic development. Neuron 8: 573-87.

Tsiang H 1993. Pathophysiology of rabies virus infection of the nervous system. Adv Virus Res 42: 375-12.

Tsiang H, Koulakoff A, Bizzini B, Berwald-Netter Y 1983. Neurotropism of rabies virus. J Neuropathol Exp Neurol 42: 439-52.

Tsiang H, Licke E, Ceccaldi P-E, Ermine A, Hirardot X 1989. The anterograde transport of rabies virus in rat sensory dorsal root ganglia neurons. J Gen Virol 70: 2075-85.

Vesanen M, Salminen M, Wessman M, Lankinen H, Sistonen P, Vaheri A 1994. Morphological differentiation of human SH-SY5Y neuroblastoma cells inhibits human immunodeficiendy virus type 1 infection. J Gen Virol 75: 201-206. 
624 Adult Mouse DRG Neurons Infection by Rabies Virus - J Castellanos et al. 